\title{
THE LETTERS OF
}

\section{Henry Wadsworth Longfellow}

$$
\begin{aligned}
& \text { VOLUME V } \\
& \text { I } 866-\text { I } 874
\end{aligned}
$$




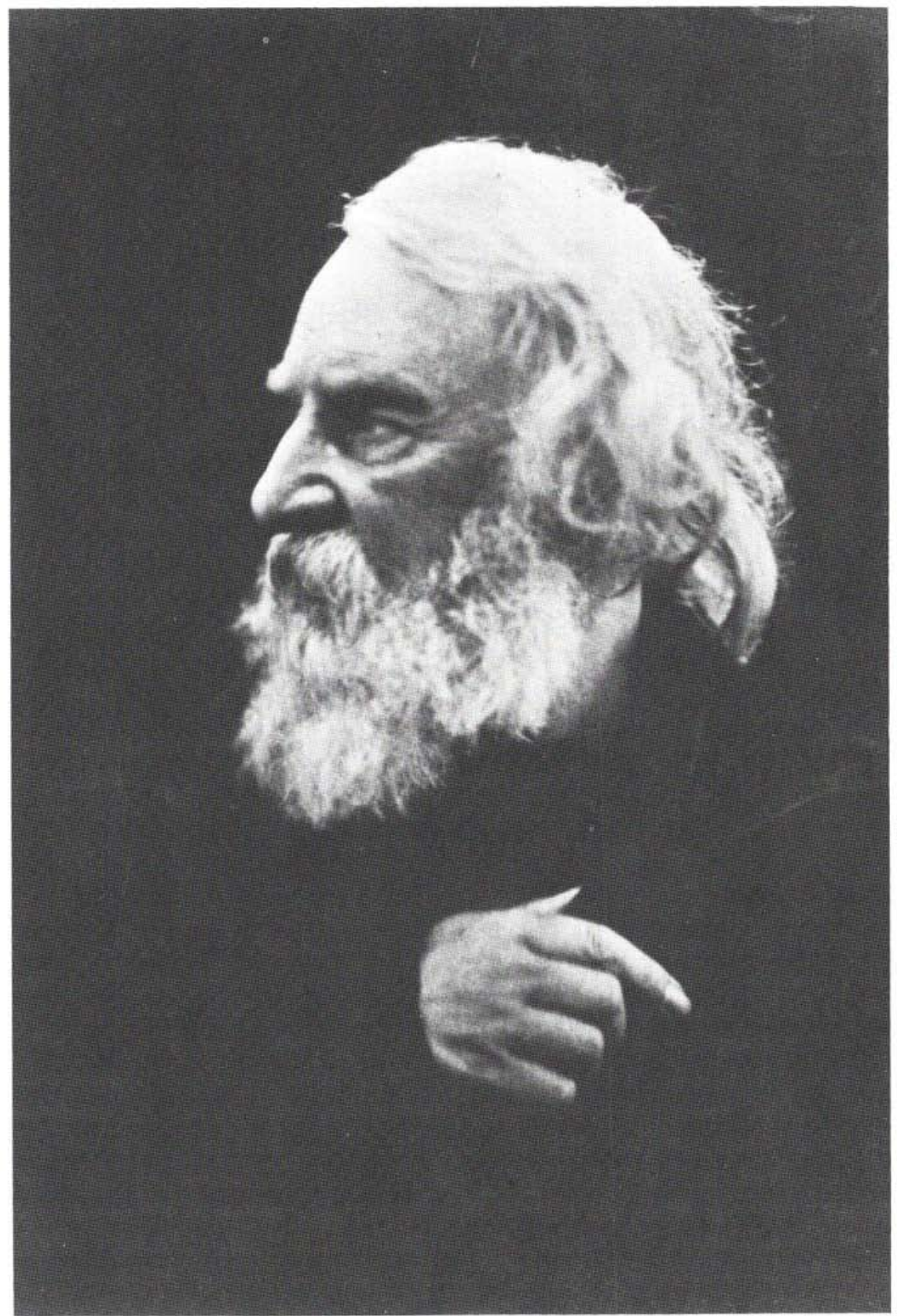

Longfellow, I 868, photograph by Julia Margaret Cameron 


\title{
THE LETTERS OF
}

\section{Henry Wadsworth Longfellow}

\author{
EDITED BY \\ Andrew Hilen
}

VOLUME V

I $866-$ I 874

The Belknap Press of Harvard University Pres ambridge, Massachusetts, and London, Englan. 1982 
Copyright (C) 1982 by the President and Fellows of Harvard College All rights reserved

Printed in the United States of America

Library of Congress Cataloging in Publication Data (Revised)

Longfellow, Henry Wadsworth, I807-1882.

The letters of Henry Wadsworth Longfellow.

Includes bibliographies.

CONTENTS: v. I. $1814-1836 .-v .2 .1837-1843 .-[$ etc.]

-v. 5. $1866-1874$.

1. Longfellow, Henry Wadsworth, 1807-1882-Corre-

spondence. 2. Poets, American - I 9 th century - Corre-

spondence. I. Hilen, Andrew R., 1913- ed.

II. Title.

$$
\begin{aligned}
& \mathrm{PS}_{22} 8_{1} \cdot A_{3} \mathrm{H}_{5} \quad 8 \mathrm{II}^{\prime} \cdot 3[B] \quad 66-18248 \\
& \text { ISBN 0-674-52728-3 AACR I } \\
& \text { ISBN 0-674-52729-1 (v. } 5 \text { and 6) }
\end{aligned}
$$

